\title{
The Sraffian supermultiplier as an alternative closure for heterodox growth theory*
}

\author{
Franklin Serrano and Fabio Freitas** \\ Instituto de Economia, Universidade Federal do Rio de Janeiro (UFRJ), Brazil
}

\begin{abstract}
This paper aims to show that the Sraffian supermultiplier model provides an alternative closure for the heterodox analysis of economic growth. The new closure follows from the assumption of the existence of autonomous non-capacity-creating expenditures, which implies that the ratio of the average to the marginal propensity to save is an endogenous variable whose determination allows the marginal propensity to invest to determine the saving ratio without the need for changes in income distribution. Provided it is also assumed that capitalist competition leads to gradual changes in the marginal propensity to invest in order to adjust productive capacity to demand, the new closure (in contrast to the Cambridge and neoKaleckian closures) allows us to reconcile demand-led growth, exogenous distribution, and a tendency towards normal capacity utilization.
\end{abstract}

Keywords: effective demand, economic growth, income distribution, capacity utilization, theoretical closures

JEL codes: $E 11, E 12, O 41$

\section{INTRODUCTION}

This paper has two purposes. The first is to show how the Sraffian supermultiplier model provides an alternative closure for the analysis of the relationships between economic growth, income distribution, capacity utilization, and effective demand in heterodox growth models. This new closure follows from the variability of ratio of the average to the marginal propensity to save, which is entailed by the assumption of the existence of (independently growing) autonomous expenditures that do not create capacity for the private sector. This allows the marginal propensity to invest to determine the

\footnotetext{
* The authors acknowledge the financial support of the National Council for Scientific and Technologial Development, CNPQ.

** Corresponding author: Fabio Freitas, email: fabio@ie.ufrj.br. The authors would like to thank Marc Lavoie and Sergio Cesaratto for discussions and encouragement, two anonymous referees for very useful suggestions and correction of mistakes, as well as comments by the participants at the 43rd Meeting of the National Association of Postgraduate Programs in Economics (ANPEC, Florianópolis, Brazil), the 19th Conference of the Research Network Macroeconomics and Macroeconomic Policies (Berlin, Germany), and the 42nd Eastern Economic Association Annual Conference (Washington, DC, USA), and research seminars at the University of São Paulo (USP, São Paulo, Brazil), at the Fluminense Federal University (UFF, Niteroi, Brazil), and at the Federal University of Espírito Santo (UFES, Vitória, Brazil), where earlier drafts of the paper were presented. Any remaining errors are our own.
}

Received 5 May 2016, accepted 29 August 2016 
saving ratio without the need for changes in income distribution (and more generally, in the marginal propensity to save). If it is also assumed that changes in the marginal propensity to invest are induced by the competitive need to gradually adjust capacity to demand, this adjustment by means of endogenous changes in the ratio of the average to the marginal propensity to save (the fraction) provides a closure that allows us to reconcile demand-led growth, exogenous distribution, and a tendency towards normal capacity utilization, even across steady states.

The second purpose of the paper is to compare and contrast this new closure with the closures associated with both the Cambridge and the neo-Kaleckian growth models. The closure provided by the Cambridge model involves the endogenous determination of income distribution, while the one associated with the neo-Kaleckian model operates through the determination of an equilibrium value for the degree of capacity utilization. The comparative analysis aims to establish the key distinctive features of the supermultiplier growth model with its alternative closure.

The rest of the paper is organized as follows. Section 2 first presents the Sraffian supermultiplier model and how its closure operates as capacity adjusts to demand, and then shows the results of permanent effects of changes in the rate of growth of autonomous consumption and in income distribution in the model. Section 3 compares the Sraffian supermultiplier model with the Cambridge and the neo-Kaleckian growth models. Section 4 contains some brief final remarks.

\section{THE SRAFFIAN SUPERMULTIPLIER GROWTH MODEL}

\subsection{Basic assumptions and relations}

For simplicity and ease of comparison we shall use the simplest possible version of each model. Hence, we assume a closed capitalist economy without a government sector. The only method of production in use requires a fixed combination of a homogeneous labor input with homogeneous fixed capital to produce a single product. Natural resources are supposed to be abundant, constant returns to scale prevail, and there is no technological progress. We also assume that growth is not constrained by labor scarcity. Moreover, all variables are measured in real terms, and output, income, profits, investment, and saving are all presented in gross terms. The formal analysis will use continuous time for mathematical convenience.

Under these assumptions, the level of full capacity output depends on the level of the capital stock and on the technical-capital-to-capacity-output ratio as:

$$
Y_{K t}=\left(\frac{1}{v}\right) K_{t},
$$

where $Y_{K t}$ is the level of capacity output, $K_{t}$ is the level of capital stock installed in the economy, and $v$ is the technical-capital-to-capacity-output ratio. Since $v$ is given, then the rate of growth of capacity output is equal to the rate of capital accumulation:

$$
g_{K t}=\left(\frac{I_{t} / Y_{t}}{v}\right) u_{t}-\delta,
$$

where $g_{K t}$ is the rate of capital accumulation, $u_{t}=Y_{t} / Y_{K t}$ (with $0 \leq u_{t} \leq 1$ ) is the actual degree of capacity utilization defined as the ratio of the current level of aggregate output $\left(Y_{t}\right)$ to the current level of capacity output, $I_{t} / Y_{t}$ is the investment share in aggregate 
output defined as the ratio of gross aggregate investment $\left(I_{t}\right)$ to the level of gross aggregate output, and $\delta$ is the exogenously given depreciation (and replacement) rate of the capital stock. ${ }^{1}$ According to equation (2), there is a necessary formal relation between the rate of capital accumulation, the actual degree of capacity utilization, and the investment share of output. Given the capital-to-capacity-output ratio, the change in the actual degree of capacity utilization depends on the difference between the rate of growth of output and the rate of capital accumulation:

$$
\dot{u}=u_{t}\left(g_{t}-g_{K t}\right)
$$

where $g_{t}$ is the rate of growth of aggregate output.

We shall use here the version of the Sraffian supermultiplier model presented in Freitas/ Serrano (2015). The model assumes that income is distributed as wages and gross profits. There is a given single technique in use, and income distribution (either the normal real wage or the normal rate of profits) is also exogenously determined along classical (Sraffian) lines. There is free competition, and output (but not capacity) adjusts fairly quickly to effective demand, implying that market prices are equal to normal prices that yield a uniform rate of profits on capital using the dominant technique when the actual degree of capacity utilization $u_{t}$ is equal to the normal or planned degree $\mu .^{2}$ Note that we work with the concept of normal prices even when dealing with situations in which the actual degree of capacity utilization can be quite different from the normal degree because under classical competition, individual firms do not have the power to sustain higher-than-normal prices when the actual degree of capacity utilization of a particular firm is below (or very much above) the normal level and their actual unit costs are higher than normal. ${ }^{3}$ Both actual competition of existing firms as well as potential competition of new entrants would ensure that effective demand will be met at the normal price even if the actual degree of capacity utilization is quite different from the normal or planned degree. ${ }^{4}$

Since we are assuming that output adapts quickly to demand, aggregate demand determines the level of aggregate output. ${ }^{5}$ Effective demand consists of aggregate consumption and investment. We suppose that aggregate consumption has an induced component and

1. We derive the capital stock growth equation from equation $I_{t}=\dot{K}+\delta K_{t}$ which defines the level of aggregate gross fixed investment as follows. Dividing both sides of this equation by $K_{t}$ we obtain $I_{t} / K_{t}=g_{K t}+\delta$ and thus $g_{K t}=\left(I_{t} / K_{t}\right)-\delta=\left(I_{t} / Y_{t}\right)\left(Y_{t} / Y_{K t}\right)\left(Y_{K t} / K_{t}\right)-\delta=$ $\left(\left(I_{t} / Y_{t}\right) / v\right) u_{t}-\delta$

2. Following Ciccone $(1986 ; 1987)$, we interpret the normal or planned degree of capacity utilization as determined, among other things, by the historically 'normal' ratio of average-to-peakdemand. This latter ratio, because it is presumably based on the observation of the actual cyclical and seasonal patterns of the market over a very long period of time, is assumed to be unaffected by current oscillations of demand.

3. If the actual degree of utilization is below the normal degree, the fixed cost per unit of output will be higher than normal. If the degree of utilization is just above the normal degree, unit costs will keep falling (giving rise, at normal prices, to extra profits) until, at capacity utilization rates substantially above normal, the cost will begin to rise due to the extra expenses involved in operating capacity way above its cost-minimizing range (Ciccone 1987).

4. Normal price is thus a kind of entry-preventing 'limit price' in the language of the old industrial organization literature (for example, Sylos-Labini 1962). For the case of 'fixprice' markets, see Lee (1999). Some Sraffians make the same argument in terms of the uniformity of expected rates of profit on new investment (Ciccone 1986; 2011; Garegnani 1992).

5. We are implicitly assuming that either 'short-term expectations' are always realized or that they are quickly revised in light of recent experience. 
an autonomous one. The former is related to the purchasing power introduced to the economy by the production decisions of capitalist firms when they pay wages. We assume that all wages are consumed and, therefore, the marginal propensity to consume of the economy is equal to the wage share, $c=\omega$. On the other hand, the autonomous component $Z_{t}$ is that part of aggregate consumption financed by credit and, therefore, unrelated to the current level of output resulting from firms' production decisions (this implies that the marginal propensity to consume out of current profits is zero). We suppose that autonomous consumption grows at an exogenously given rate, $g_{Z}>0$.

Capitalist firms undertake all investment (that is, we abstract from residential investment). Further, we assume that the capital stock adjustment principle explains the behavior of aggregate investment. According to this principle, inter-capitalist competition influences the process of investment leading to the tendency towards the adjustment of productive capacity to meet demand at a price that covers the production expenses and allows, at least, the obtainment of a minimum required profitability. Thus, the capital stock adjustment principle conceives the demand for capital goods as a derived demand with the objective of creating capacity to meet profitable (or effective) demand. ${ }^{6}$ The level of aggregate real investment is determined as follows:

$$
I_{t}=h_{t} Y_{t},
$$

where $h_{t}$ (with $0 \leq h_{t}<1$ ) is the marginal propensity to invest. How the latter slowly changes endogenously over time will be discussed further below.

Given these assumptions, the level of aggregate demand determines a positive level of aggregate output provided that we further assume that the marginal propensity to spend, $c+h_{t}$, is strictly lower than one and that there is a positive level of autonomous consumption (or, more generally, a positive level of autonomous non-capacity-creating expenditures). The demand-determined level of output is:

$$
Y_{t}=\left(\frac{1}{s-h_{t}}\right) Z_{t},
$$

where $s=1-\omega$ is the given aggregate marginal propensity to save. The term within the parentheses is the supermultiplier that captures the effects on the level of output associated with both induced consumption and investment.

According to the model, the investment share of output (that is, the marginal propensity to invest) determines the saving ratio (average propensity to save). This endogenous determination of the saving ratio follows from the assumption that there exists a positive level of autonomous consumption. Indeed, given $Z_{t}>0$, the marginal propensity to invest is equal to and determines the saving ratio as follows:

$$
\frac{S_{t}}{Y_{t}}=s-\frac{Z_{t}}{Y_{t}}=s f_{t}=\frac{I_{t}}{Y_{t}}=h_{t},
$$

where $f_{t}$ is what is called 'the fraction' in Serrano (1995b), defined as the ratio of the average to the marginal propensities to save, $f_{t}=\left(S_{t} / Y_{t}\right) / s=I_{t} /\left(I_{t}+Z_{t}\right) .{ }^{7}$ With positive levels of autonomous consumption, it follows that $f_{t}<1$ and $S_{t} / Y_{t}<s$. Therefore, the given marginal propensity to save defines only an upper limit to the value of the saving

6. See Goodwin (1951) and Chenery (1952). See also Matthews (1959) for a more detailed account of the capital stock adjustment principle.

7. According to equation (6), if there were no autonomous consumption (that is, $Z_{t}=0$ ) then $f_{t}=1$ and $S_{t} / Y_{t}=s$. That is, the marginal propensity to save determines the saving ratio. Note also 
ratio of the economy corresponding to a given marginal propensity to save associated with a given level of income distribution. Hence, in the case under analysis, the saving ratio depends not only on the marginal propensity to save but also on the proportion between autonomous consumption and investment. Thus, an increase (decrease) in the levels of aggregate investment in relation to autonomous consumption leads to an increase (decrease) in the saving ratio. Consequently, the existence of a positive level of autonomous consumption is sufficient to make the saving ratio an endogenous variable. Therefore, for a given level of income distribution (and consumption habits) and, hence, a given marginal propensity to save, the marginal propensity to invest, $h_{t}$ (equal to the investment share of output), uniquely determines the saving ratio of the economy. This endogenous determination of the saving ratio, with a given level of income distribution, is the distinctive feature of the closure provided by the Srafffian supermultiplier growth model.

The marginal propensity to invest changes endogenously in response to deviations of the actual degree of capacity utilization from its normal level as follows:

$$
\dot{h}=h_{t} \gamma\left(u_{t}-\mu\right)
$$

where $\gamma$ is a parameter that measures the reaction of the growth rate of the marginal propensity to invest to the deviation of the actual degree of capacity utilization, $u_{t}$, from its normal or planned level, $\mu$. We suppose that the normal degree of capacity utilization has a positive but lower-than-one value (that is, $0<\mu<1$ ) since we assume, as explained above, that under the pressure of competition firms try to maintain margins of planned spare capacity to avoid the risk of losing market share for not being able to supply the demand peaks. On the other hand, we assume that the parameter $\gamma$ has a small positive value (that is, $\gamma>0$ ). The reason for that is that it makes no sense for firms to attempt to adjust the whole of the stock of fixed capital fully to every single fluctuation in demand for two main reasons. The first is that firms want normal utilization to prevail on average over the lifetime of the productive equipment and not in every single period of use. The second is that firms also know that demand does fluctuate and some of the fluctuations are temporary, while others are not (though it is not easy to distinguish between the two quickly).

Together, equations (4) and (7) imply that investment grows according to:

$$
g_{I t}=g_{t}+\gamma\left(u_{t}-\mu\right) \text {. }
$$

The growth rate of aggregate investment will thus be higher than the growth rate of demand (and hence of output) whenever the actual degree of capacity utilization is above its normal or planned level and vice versa. The pressure exerted by competition would ensure that firms as a whole would be compelled to invest in order to ensure that they can meet future peaks of demand when the degree of capacity utilization is above the normal (or planned) degree and the margins of spare capacity are getting too low. Conversely, firms would not want to keep accumulating costly, unneeded spare capacity when the actual degree of capacity utilization remains below the profitable normal or planned level.

From our assumptions, we can also obtain the following equation for the growth rate of aggregate output/demand: ${ }^{8}$

that, in this extreme case, the equilibrium between aggregate demand and aggregate output with a given income distribution also implies the endogenous determination of the investment share of output by the given marginal propensity to save.

8. The equation is deduced as follows. Taking the time derivatives of the endogenous variables involved in expression $Y_{t}=Z_{t}+c Y_{t}+h_{t} Y_{t}$ and dividing both sides of the resulting equation by the level of aggregate output, we obtain $g_{t}=c g_{t}+h_{t} g_{t}+\dot{b}+\left(Z_{t} / Y_{t}\right) g_{Z}$. If $Z_{t} / Y_{t}=s-h_{t}>0$, then 


$$
g_{t}=g_{Z}+\frac{h_{t} \gamma\left(u_{t}-\mu\right)}{s-h_{t}} .
$$

Equation (9) shows that when actual and normal degrees of capacity utilization are different, the rate of growth of output and demand is determined by the rate of expansion of autonomous consumption plus the rate of change of the supermultiplier given by the second term on the right-hand side of the equation.

Let us now substitute equations (9) and (2) into equation (3). From the combination of the resulting equation and equation (5) we obtain a system of two first-order non-linear differential equations in two variables, the share of investment in output $h$, and the actual degree of capacity utilization $u$ :

$$
\begin{gathered}
\dot{h}=h_{t} \gamma\left(u_{t}-\mu\right) \\
\dot{u}=u_{t}\left(g_{Z}+\frac{h_{y} \gamma\left(u_{t}-\mu\right)}{s-h_{t}}-\left(\frac{h_{t}}{v}\right) u_{t}+\delta\right) .
\end{gathered}
$$

\subsection{The adjustment of capacity to demand}

The process of adjustment of capacity to demand requires the fulfillment of two conditions. First, the investment share of output must be susceptible to changes according to the logic of the capital stock adjustment principle. This condition is strictly necessary because only if the level of investment can increase at a different pace than aggregate demand and output, it is logically possible to make the capital stock and capacity tend to grow faster than demand if there is persistent overutilization (and more slowly than demand when there is underutilization) and thus we can speak of a tendency of capacity to adjust to demand. Such changes in the investment share are possible because of the existence of an autonomous consumption component of aggregate demand. In fact, from equations (8) and (9) we can obtain the following relations:

$$
g_{I t} \gtreqless g_{t} \gtreqless g_{Z} \text { as } u_{t} \gtreqless \mu \text {. }
$$

According to them, if the actual degree of capacity utilization is above (below) the normal level, the marginal propensity to invest increases (decreases). At the same time, the saving ratio $\left(S_{t} / Y_{t}=s f_{t}\right)$ also increases (decreases) because the growth rate of investment is higher (lower) than the growth rate of autonomous consumption and, therefore, the fraction $f_{t}=I_{t} /\left(I_{t}+Z_{t}\right)$ increases (decreases) while the marginal propensity to save is constant. These changes in the investment share of output in response to deviations from the normal degree of capacity utilization are necessary for the adjustment of capacity to demand and the corresponding tendency towards a fully adjusted position of the model. However, they are not sufficient to assure such a result since the intensity of the adjustment must also be considered.

we can solve the last equation for the rate of growth of aggregate output and demand, obtaining $g_{t}=g_{Z}+\dot{b} /\left(s-h_{t}\right)$. Finally, we can substitute the right-hand side of equation (7) in the second term on the right-hand side of the last equation, which gives us equation (9). 
Thus an additional condition is required, according to which the marginal propensity to invest changes gradually in response to deviations of the actual degree of capacity utilization from its planned level. The latter is required to assure that the value of the marginal propensity to spend remains lower than one throughout the process of convergence to the fully adjusted position. The reason for that is quite simple. Given that empirically it is plausible that normal technical-capital-to-capacity-output ratios for fixed capital tend to be greater than one, an immediate and full reaction of induced investment that tried to adjust capacity drastically to any current deviation from normal utilization would certainly lead to a marginal propensity to invest greater than one. Since the marginal propensity to consume is positive, the overall marginal propensity to spend in the vicinity of the fully adjusted position would be greater than one, which would lead to the instability of the adjustment process. Such drastic adjustment of the investment share seems, however, highly unrealistic, as we argued above, both because of the durability of fixed capital (which means that producers want normal utilization only on average over the life of equipment and not at every moment) and also because producers know that demand fluctuates a good deal and, therefore, do not interpret every fluctuation in demand as indicative of a lasting change in the trend of demand (the capital stock adjustment principle is thus based on a 'flexible' accelerator).

This additional condition implies that the local dynamic stability of the fully adjusted equilibrium requires that the aggregate marginal propensity to spend in the neighborhood of the fully adjusted equilibrium must be lower than one (see Freitas/Serrano 2015 for the proof). Here we consider that this stability condition is met by assuming that the value of the reaction parameter $\gamma$ is sufficiently low, such that:

$$
c+\frac{v}{\mu}\left(g_{Z}+\delta\right)+\gamma v<1 .
$$

We can interpret (12) as an expanded marginal propensity to spend that, besides the final equilibrium propensity to spend (that is, $c+(v / \mu)\left(g_{Z}+\delta\right)$ ), ${ }^{9}$ includes also a term (that is, $\gamma v$ ) related to the behavior of induced investment outside the fully adjusted position. The extra adjustment term captures the fact that outside the fully adjusted positions there must be room not only for the induced gross investment necessary for the economy to grow at its final equilibrium rate $g_{Z}$, but also for the extra induced investment responsible for adjusting capacity to the trend of demand.

\subsection{The fully adjusted position}

Let us assume that the parameters are such that the model is stable. The model will then be always tending towards the fully adjusted position in which capacity adjusts to demand and, thus, we have $u_{t}=u^{*}=\mu$. From equations (7) and (9) we can see that in the fully adjusted position of the Sraffian supermultiplier model the growth rates of output, demand, and investment are equal to the growth rate of autonomous consumption. Moreover, since $\dot{u}=0$ and $\mu>0$, then, from equation (3), the rate of capital accumulation is equal to the growth rate of output. Hence, in the fully adjusted equilibrium we have $g_{K}^{*}=g_{I}^{*}=g^{*}=g_{Z}$. That is, the growth rate of autonomous consumption determines the equilibrium growth rates of the capital stock, investment, and output/demand. The model generates an equilibrium path where economic growth is consumption-led (or, more generally, growth is led by autonomous non-capacity-creating expenditures).

9. As we will see in the following section, the value of the marginal propensity to invest in equilibrium is given by $h^{*}=(v / \mu)\left(g_{Z}+\delta\right)$. See equation (13). 
The last result shows that, according to the model, the growth of autonomous consumption drives the pace of capital accumulation and, therefore, the growth of productive capacity. Such a result is compatible with the maintenance of a normal (or planned) degree of capacity utilization throughout the equilibrium path (and a tendency of the economy to converge towards this path) because the investment share of output (that is, the marginal propensity to invest) will tend to a required value $b^{*}$ given by:

$$
h^{*}=\frac{v}{\mu}\left(g_{Z}+\delta\right) \text {. }
$$

The required investment share is uniquely determined by the rate of growth of autonomous consumption, the technical-capital-to-capacity-output ratio, the normal degree of capacity utilization and the rate of depreciation.

The saving ratio (or average propensity to save) is an endogenous variable and its equilibrium value in the fully adjusted position is determined by the required level of the investment share of output. As we mentioned above, the endogeneity of the saving ratio in the model is a consequence of the hypothesis of the existence of a positive level of autonomous consumption. Actually, the latter hypothesis makes it possible for the fraction $f_{t}=h_{t} / s$ to change its value according to the modifications of the investment share of output. As a result, $Z_{t} / Y_{t}=s\left(1-f_{t}\right)=s-h_{t}$, the ratio of autonomous consumption to aggregate output can change, making the saving ratio an endogenous variable and allowing its adjustment to the investment share of output. In fact, along the equilibrium path of the model, once the investment share is determined by equation (13) we can obtain the equilibrium values of the fraction, of the aggregate autonomous consumption/output ratio, and, accordingly, of the equilibrium value of the saving ratio as follows:

$$
\begin{gathered}
f^{*}=\frac{b^{*}}{s}=\frac{\frac{v}{\mu}\left(g_{Z}+\delta\right)}{s} \\
\left(\frac{Z_{t}}{Y_{t}}\right)^{*}=s\left(1-f^{*}\right)=s-b^{*}=s-\frac{v}{\mu}\left(g_{Z}+\delta\right)
\end{gathered}
$$

and

$$
\left(\frac{S_{t}}{Y_{t}}\right)^{*}=s-\left(Z_{t} / Y_{t}\right)^{*}=s f^{*}=b^{*}=\frac{v}{\mu}\left(g_{Z}+\delta\right) .
$$

The endogenous determination of the saving ratio with a given distribution of income associated with the supermultiplier growth model supplies us with an alternative closure for the analysis of the relationships between economic growth, income distribution, capacity utilization, and effective demand. Indeed, substituting the expression for the saving ratio in equation (6) into equation (2) we obtain:

$$
g_{K t}=\left(\frac{s f_{t}}{v}\right) u_{t}-\delta .
$$

Now, we just saw that in the fully adjusted equilibrium of the supermultiplier growth model normal capacity utilization prevails. Thus, the fraction $f$ is the only variable that can be adjusted in order to reconcile the rate of capital accumulation with the exogenously given rate of growth of autonomous consumption. Therefore, for the fully adjusted 
equilibrium to be possible, the fraction $f$ must assume the value given by equation (14) above, which represents the closure provided by the Sraffian supermultiplier model.

Finally, by introducing the required level of the investment share $b^{*}$ into equation (7), we obtain the fully adjusted level of output:

$$
\frac{\mu K^{*}}{v}=Y_{t}^{*}=Y_{t}=\left(\frac{1}{s-\frac{v}{\mu}\left(g_{Z}+\delta\right)}\right) Z_{t} .
$$

Equation (17) shows that for each $t$ along the equilibrium path, the level of autonomous consumption and the fully adjusted (final equilibrium) level of the supermultiplier (the term within the parentheses) determine the levels of output of the fully adjusted positions (final equilibria) towards which the economy slowly gravitates. Thus in the fully adjusted positions of the supermultiplier growth model not only aggregate output but also the levels of capacity output and the capital stock adjust to the levels of aggregate demand.

As we saw above, the rate of growth of autonomous consumption determines the trend rate of growth of demand and output. Since there is a tendency towards normal capacity utilization, then changes in $g_{Z}$ also have a growth effect on capacity output. Hence a permanent rise (fall) in $g_{Z}$ causes a permanent increase (decrease) in $g_{K}^{*}$. As this effect of $g_{Z}$ on the pace of capital accumulation $g_{K}^{*}$ occurs through the effect of $g_{Z}$ on the equilibrium level of the investment share of output (that is, $b^{*}$ ), from equation (13) we can see that a permanent increase (fall) in $g_{Z}$ also has a positive (negative) level effect on $h^{*}$. Moreover, from equations (14) to (16) we can observe that a rise (fall) in $g_{Z}$ has, on the one hand, a positive (negative) level effect on the equilibrium value of the fraction (that is, $f^{*}$ ) and on the equilibrium level of the saving ratio (that is, $\left(S_{t} / Y_{t}\right)^{*}=s f^{*}$ ) and, on the other, a negative (positive) level effect on the equilibrium level of the autonomous consumption to output ratio (that is, $\left(Z_{t} / Y_{t}\right)^{*}=s\left(1-f^{*}\right)$ ). Therefore, the Sraffian supermultiplier growth model implies the existence of a positive causal relationship running from the trend rate of growth of output/demand to the investment share of output and the saving ratio.

On the other hand, our analysis has shown that the equilibrium rates of growth of output/demand and of the capital stock are independent from the value of the wage share (and more generally of the marginal propensity to save). Hence, in the Sraffian supermultiplier model there is no direct relationship between income distribution and the equilibrium rate of growth of output and demand. Given that changes in income distribution do not have a permanent growth effect on output, then (as equation (13) shows) such changes do not have a permanent effect on the equilibrium value of the investment share of output either. Nevertheless, changes in income distribution do have level effects. A change in income distribution affects, by means of its influence over the marginal propensity to consume (save), the equilibrium value of the supermultiplier and, hence, the equilibrium value of aggregate output. Thus, the model is subject to wage-led output-level effects.

Changes in income distribution do affect the marginal propensity to save. In fact, since the latter is here equal to the profit share (that is, $s=1-\omega$ ), an increase (decrease) in the wage share would reduce (raise) the marginal propensity to save. Making use of equations (14) and (16) we can verify how this latter result is reconciled with the invariability of the saving ratio in relation to a change in income distribution. Given the value of the investment share of output, an increase (decrease) in the marginal propensity to save leads to a fall (rise) in the fraction that always exactly compensates it $\left(\right.$ since $\left.f^{*}=b^{*} / s\right)$. 


\section{A COMPARISON WITH OTHER HETERODOX MODELS ${ }^{10}$}

In this section, we shall compare the Sraffian supermultiplier growth model with the Cambridge and neo-Kaleckian growth models, trying to point out their similarities and, more importantly, their main differences.

\subsection{Cambridge growth models}

Maintaining the hypothesis of permanent labor surplus, in the Cambridge growth model ${ }^{11}$ the level of aggregate output is determined in the long run by the level of capacity output, and aggregate demand adjusts itself endogenously to this given level. So, contrary to the Sraffian supermultiplier growth model, the equilibrium level of aggregate output is not determined by effective demand, but by the level of output associated with full utilization of the given productive capacity. Thus we have:

$$
Y_{t}=Y_{K t}=\frac{1}{v} K_{t}
$$

and

$$
u^{*}=1 \text {. }
$$

Also differently from the Sraffian supermultiplier, there is no autonomous consumption, and besides the consumption induced by the wage bill, there is also a component of aggregate consumption induced by total current profits. We retain here the assumption that all wages are consumed (that is, the propensity to consume out of wages $c_{w}$ is equal to one) and suppose that the marginal propensity to consume out of profits $c_{\pi}$ is a positive constant and has a value lower than one (that is, $0<c_{\pi}<1$ ). Thus the consumption function is given by the following expression:

$$
C_{t}=\left(\omega_{t}+c_{\pi}\left(1-\omega_{t}\right)\right) Y_{t}
$$

where $\omega_{t}+c_{\pi}\left(1-\omega_{t}\right)$ is the marginal propensity to consume out of aggregate income, which is equal to the average propensity to consume since there is no autonomous component in the consumption function. Moreover, in contrast to the supermultiplier growth model, capacity-creating investment is an autonomous expenditure in this version of the Cambridge model, and we suppose, for the sake of simplicity, that investment simply expands at an exogenously determined rate, $g_{I}>0$, perhaps determined by 'animal spirits.' From these hypotheses we obtain the aggregate demand equation of the Cambridge model:

$$
D_{t}=\left(\omega_{t}+c_{\pi}\left(1-\omega_{t}\right)\right) Y_{t}+I_{t}
$$

Since aggregate output in the long run is determined by capacity output, the equilibrium between aggregate demand and output requires that the former adjusts to the latter. In the Cambridge model such an adjustment involves a change in the aggregate marginal

10. This section is based on and confirms the main findings contained in the more general comparative analysis presented in Serrano (1995b: ch. 3).

11. See Robinson (1962). For similar formalizations of the Cambridge growth model, see Dutt (1990; 2011) and Lavoie (2014). 
propensity to consume through the modification of income distribution (that is, of the wage share). Thus, according to the model, a situation of initial excess aggregate demand (supply) raises (reduces) the general price level and, with a relatively rigid nominal wage, it causes a decrease (increase) in real wages. So, given labor productivity, the excess aggregate demand (supply) causes a reduction (increase) in the wage share $\omega$ and, since $0<c_{\pi}<c_{w}=1$, it causes a decline (rise) in the marginal propensity to consume.

This pricing mechanism, in which profit margins are demand-determined and 'flexible' relative to costs is remarkably unrealistic, especially in the long run in both directions. On one hand, profit-seeking firms would quickly contract output when profit margins (and hence the profit share) fell below a required minimum (and would fall to zero immediately when prices fell below costs). On the other hand, if the supply constraint consists of capital, the situations of chronic excess demand for goods that would increase prices and profit margins would tend to be temporary. The high level of investment that is requiring the 'forced saving' brought about by the change in distribution would itself in the longer run tend to create productive capacity and eliminate the cause of the demand inflation.

Some authors claim that the Cambridge mechanism of endogenous distribution would work in competitive markets while exogenous distribution would be the characteristic of oligopolistic economies. ${ }^{12}$ However, this argument is not plausible. In fact, in a longer run, prices of produced goods always depend on costs, no matter what is the market structure. And in the short run, if supply constraints are binding, profit margins are also bound to be 'flexible' upwards in any form of market structure. Moreover, the basic idea of the Cambridge model, that output supply is less elastic in the long run than in the short, is unrealistic, as the capacity effect of investment becomes more significant in the long run. ${ }^{13}$

In any case, this implausible adjustment mechanism has been widely adopted in the Cambridge model literature and it definitely implies a tendency for the establishment of an equilibrium between aggregate demand and supply at the level of capacity output (that is, the level of potential output), which in equilibrium determines the level of aggregate demand. ${ }^{14}$ At the same time, in equilibrium between aggregate demand and output capacity, the model endogenously determines the distribution of income between wages

12. See, for instance, Robinson (1962) and Steindl (1989).

13. For critiques of this type of long run 'flexibility' of profit margins, see Davidson (1972), Vianello (1985), and Serrano (1995b).

14. Note that the adjustment mechanism based on endogenous changes of income distribution guarantees the adjustment of aggregate demand to the level of potential output whatever is the binding constraint that determines the latter. It does not guarantee the adjustment of the degree of capacity utilization to its full capacity level when capital is not the biding constraint on output. As Kaldor $(1955 / 1956)$ argued in his seminal discussion of the adjustment of aggregate demand to potential output through changes in distribution, the latter can be viewed as an alternative to the usual Keynesian adjustment of output to aggregate demand. In the present version of the Cambridge growth model, the maintenance of a full utilization of capacity resulting from the operation of the adjustment mechanism involving changes in income distributions is a consequence of the assumption that the binding supply constraint in the economy is the availability of capital. If the operative supply constraint was the full employment of the labor force, then the adjustment of aggregate demand to potential output based on endogenous changes in income distribution would not guarantee the full (or the normal) utilization of the available capital stock. In Kaldor's full employment growth models (cf. Kaldor 1957 [1960]; 1958 [1978]; 1962 [1978]), since capital and labor are complementary factors and there is 'capital surplus,' an induced investment function is responsible for the adjustment of the degree of capacity utilization as it makes the level and growth of the capital stock adjust itself to the exogenous levels and rates of growth of full employment output. For an analysis of this role of the investment functions in Kaldor's full employment growth models, see Freitas (2002: ch. 2; 2009). 
and profits. So, in the Cambridge model, the determination of a required level of income distribution allows the adjustment of aggregate demand to potential output, while in the Sraffian supermultiplier growth model it is the appropriate change in the level of aggregate output that explains the adjustment of aggregate output to the level of aggregate demand.

Now, in equilibrium between aggregate output and aggregate demand, we have $Y_{t}=$ $\left(\omega^{*}+c_{\pi}\left(1-\omega^{*}\right)\right) Y_{t}+I_{t}$ and, thus:

$$
S_{t}^{*}=s^{*} Y_{t}=s_{\pi}\left(1-\omega^{*}\right) Y_{t}=I_{t},
$$

where $s_{\pi}=1-c_{\pi}$ is the marginal propensity to save out of total profits. The last equation shows that, according to the Cambridge model, aggregate investment determines aggregate (capacity) saving, although, as we saw above, the level of potential output determines the level of real aggregate demand. Furthermore, dividing both sides of the last equation by the level of aggregate output, which will be equal to capacity output in this model, we have the expression relating the saving ratio to the investment share of output:

$$
\left(\frac{S_{t}}{Y_{t}}\right)^{*}=s^{*}=s_{\pi}\left(1-\omega^{*}\right)=\frac{I_{t}}{Y_{t}} .
$$

From the above equation we can see that in the Cambridge model the investment-capacity output ratio determines the saving ratio $s^{*}=s_{\pi}\left(1-\omega^{*}\right)$. But, since in the Cambridge model there is no autonomous consumption component, the marginal and average propensities to save are equal to each other. Hence, the burden of the adjustment of the saving ratio to the investment share on capacity output relies on required modifications in the marginal propensity to save and, therefore, on appropriate changes in income distribution.

Let us now discuss the determination of the equilibrium level of the investment share of capacity output. From the assumption of full capacity utilization, the growth rate of output is given by the rate of capital accumulation (that is, $g_{t}=g_{K t}$ ). Thus, if we have initially $g_{K t}<g_{I}\left(g_{K t}>g_{I}\right)$, then we also have $g_{t}<g_{I}\left(g_{t}>g_{I}\right)$. It follows that the investment share of output would increase (decrease) and, according to equation (2) and with the constant degree of capacity utilization, the rate of capital accumulation would increase (decrease). Eventually this type of adjustment leads to the convergence of the rate of capital accumulation to the investment growth rate. ${ }^{15}$ Therefore in the equilibrium path of the model we have:

$$
g^{*}=g_{K}^{*}=g_{I} .
$$

Substituting this last result in equation (2), solving for the investment share of capacity output and recalling that $u^{*}=1$, we have the equilibrium value of the investment share given by

$$
\left(\frac{I_{t}}{Y_{t}}\right)^{*}=v\left(g_{I}+\delta\right) .
$$

Thus, according to the Cambridge growth model, a higher (lower) rate of growth of investment implies higher (lower) equilibrium growth rates of capacity output and output.

15. The adjustment process between the rate of capital accumulation and the expansion rate of investment can also be explained as follows. As $\dot{g}_{K t}=\left(g_{K t}+\delta\right)\left(g_{I t}-g_{K t}\right)$, so, since $g_{I t}=g_{I}$, if initially $-\delta<g_{K 0} \neq g_{I}$, then the capital accumulation rate would converge to the investment growth rate because from the last differential equation we can verify that we have $\dot{g}_{K t} \gtrless 0$ according to $g_{I t} \gtrless g_{K t}$. 
Moreover, with a constant rate of capacity utilization, this result is possible because the equilibrium level of the investment to capacity output ratio is positively related to the growth rate of investment and, therefore, to the equilibrium growth rates of output and capacity output. This last result is shared by the Sraffian supermultiplier growth model, although the demand-led process by which it is achieved is different from the supply-constrained process featured in the Cambridge growth model.

It is important to note, however, that the growth-determining role of investment in the Cambridge model actually follows from its effect on productive capacity and not from its influence on aggregate demand. As we saw above, in the Cambridge growth model, the level of existing capacity output always determines endogenously a level of aggregate demand equal to it in the long run. Thus, a higher (lower) growth rate of investment only causes a higher (lower) rate of output growth because it raises (reduces) the level of the investment share of output by reducing (increasing) the share of induced consumption in both actual and capacity output. This higher share of investment in capacity increases the pace of capital accumulation and the growth of capacity (or potential) output. Therefore, the Cambridge model displays, in fact, a supply (capacity) constrained pattern of economic growth, and hence, it is definitely not a demand-led growth model.

Finally, we can substitute the expression for the equilibrium level of the investment share in the equation relating the investment share and the saving ratio. Doing this, we can obtain the following result:

$$
\left(1-\omega^{*}\right)=\frac{v\left(g_{I}+\delta\right)}{s_{\pi}} .
$$

Equation (18) shows us the determinants of the required level of income distribution in the Cambridge model. In particular, we can see that, given $v, \delta$, and $s_{\pi}$, a higher (lower) growth rate yields a higher (lower) profit share of output. Thus, according to the Cambridge growth model and in contrast with the Sraffian supermultiplier model, there exists a theoretically necessary relationship between income distribution and economic growth, the profit share of output (the wage share) being positively (negatively) related to the rate of economic growth. In the Cambridge model, such a relationship is necessary in order to obtain a growth path characterized by the equilibrium between aggregate demand and aggregate output with full capacity utilization. Therefore, the closure provided by the Cambridge model requires the endogenous determination of an appropriate level of income distribution, which must be compatible with various combinations of the values of the model's exogenous variables and parameters. ${ }^{16}$

\subsection{Neo-Kaleckian growth models}

We shall now compare the Sraffian supermultiplier and the neo-Kaleckian growth models. ${ }^{17}$ As in the supermultiplier model, in the neo-Kaleckian growth model the level of aggregate demand determines the equilibrium level of aggregate output, since in both models income

16. Contrast equation (18) with equation (14), which represents the closure provided by the Sraffian supermultiplier growth model.

17. These models descend from original contributions by Kalecki (1971) and Steindl (1952; 1979). The modern neo-Kaleckian model was presented originally by Rowthorn (1981) and Dutt (1984). Bhaduri/Marglin (1990) and Marglin/Bhaduri (1990) presented a very influential contribution to the Kaleckian literature, in which the model can deal with different types of relationship between economic growth and aggregate demand, on the one side, and income distribution, on the 
distribution is exogenously determined and, therefore, cannot be part of an adjustment mechanism that makes demand adapt to capacity as in the Cambridge model. However, in contrast to the Sraffian supermultiplier model, in the neo-Kaleckian models aggregate investment does not follow the capital stock adjustment principle. For the sake of simplicity, we will first present the model considering that aggregate investment is totally autonomous and grows at an exogenously determined growth rate $g_{I}>0$ (and we will partially relax this assumption later on in this section). ${ }^{18}$ Also, differently from the Sraffian supermultiplier model, there is no autonomous component in aggregate consumption in the neo-Kaleckian models. In fact, in our representation of the basic neo-Kaleckian model we utilize the same specification for the consumption function used in the Cambridge model above. The single, but important, difference is that in the neo-Kaleckian model the wage share is exogenously determined and, accordingly, the marginal propensity to consume (equal to the average propensity to consume) is also an exogenous variable.

With these hypotheses, aggregate demand is given by the following expression:

$$
D_{t}=\left(\omega+c_{\pi}(1-\omega)\right) Y_{t}+I_{t}
$$

and in equilibrium between aggregate demand and output we have:

$$
Y_{t}^{*}=\left(\frac{1}{s}\right) I_{t}=\left(\frac{1}{s_{\pi}(1-\omega)}\right) I_{t} .
$$

According to the last equation, aggregate investment is the main determinant of the equilibrium level of output. Further, given income distribution (that is, the wage share), the value of the multiplier $1 / s=1 /\left(s_{\pi}(1-\omega)\right)$ is constant. Thus, in the neo-Kaleckian model, as can be verified from the last equation, the pace of investment expansion determines the equilibrium output growth rate of the economy for a given level of income distribution. That is, we have

$$
g^{*}=g_{I} .
$$

Hence, as in the Sraffian supermultiplier growth model, the neo-Kaleckian model produces a demand-led growth pattern. But while in the supermultiplier model we have a consumption-led growth pattern (or, in a more general context, growth is led by

other. See also Dutt (1990) and Lavoie (2014) for a formalization and comparison of the neoKaleckian model with alternative growth models. For a detailed survey of the literature, see Blecker (2002).

18. Note that our presentation of the neo-Kaleckian model has some minor differences in relation to the usual presentation of these models. The main difference is that we specify the investment function in terms of the determinants of the growth rate of investment, while the usual neo-Kaleckian specification is in terms of the determinants of the desired rate of capital accumulation. Observe that this difference does not affect the equilibrium values of the model's endogenous variables because, since by definition $g_{I t}=g_{K t}+\dot{g}_{K} /\left(g_{K t}+\delta\right)$ and since, in equilibrium, we have $\dot{g}_{K}=0$, then in equilibrium we obtain $g_{I}^{*}=g_{K}^{*}$. Moreover, it can be shown that our specification of the investment function does not affect the equilibrium stability condition. Therefore, we claim that nothing essential is altered by our particular specification of the investment function of the neoKaleckian model. On the other hand, our specification fits our main purpose of discussing the different routes by which investment levels and shares generate the corresponding saving according to the alternative model closures. 
autonomous non-capacity-creating demand), the neo-Kaleckian model generates an investment-led pattern of economic growth.

From equation (19) we can also verify that

$$
S_{t}^{*}=s Y_{t}^{*}=s_{\pi}(1-\omega) Y_{t}^{*}=I_{t}
$$

and

$$
\frac{I_{t}}{Y_{t}^{*}}=\frac{S_{t}^{*}}{Y_{t}^{*}}=s=s_{\pi}(1-\omega) .
$$

Thus, according to the first of the two equations above, the level of aggregate saving adjusts to the level of aggregate investment through the variation of the level of aggregate output, the only endogenous variable in the equation. Note however that, based on the second equation above, since $s_{\pi}$ and $\omega$ are given, the saving ratio is an exogenous variable. Thus the saving ratio, equal to the marginal propensity to save $s$, determines the investment share of output in the neoKaleckian model. This feature of the model contrasts sharply with the related result obtained from the Cambridge and Sraffian supermultiplier growth models. Indeed, as we pointed out above, in these latter models the investment share of output determines the saving ratio. In the Cambridge model this result follows from changes in income distribution and in the marginal propensity to save, while in the Sraffian supermultiplier growth model the same result follows from the existence of an autonomous component in aggregate consumption and the fraction which makes the saving ratio endogenous even though income distribution and the marginal propensity to save are given exogenously. In contrast, the neo-Kaleckian model assumes that income distribution (and thus the marginal propensity to save) is exogenously determined and that there is no autonomous consumption component, which implies, in combination with the other assumptions of the model, the exogeneity of the saving ratio.

Now, since the saving ratio is an exogenous variable and it determines the investment share of output, then the latter variable cannot be changed according to the requirements of the pace of economic growth. So, in contrast to the Sraffian supermultiplier growth model, according to the neo-Kaleckian growth model, if income distribution is given, a change in the investment and output growth rates does not have any effect on the equilibrium value of the investment share of output, as it makes induced consumption grow at the same rate. More importantly, from equation (2) we can verify that in the neo-Kaleckian model the rate of capital accumulation can only be reconciled with the output/demand growth rate if the degree of capacity utilization is properly adjusted. Indeed, since in the neo-Kaleckian model the saving ratio determines the investment share of output, then, according to equation (2), the rate of capital accumulation is given by:

$$
g_{K t}=\left(\frac{s_{\pi}(1-\omega)}{v}\right) u_{t}-\delta .
$$

On the other hand, we saw that in the neo-Kaleckian model the growth rate of investment determines the equilibrium growth rate of output, that is, we have $g^{*}=g_{I}$. Thus, using these results in equation (3), we obtain the following differential equation for the dynamic adjustment of the degree of capacity utilization:

$$
\dot{u}=u_{t}\left(g_{I}-\left(\frac{s_{\pi}(1-\omega)}{v}\right) u_{t}+\delta\right) .
$$

Equation (20) shows that if the investment growth rate is higher (lower) than the rate of capital accumulation, then the degree of capacity utilization increases (declines) and this 
raises (reduces) the pace of capital accumulation. As a result, the rate of capital accumulation converges to the growth rate of investment through changes in the degree of capacity utilization. Therefore, in the equilibrium path of the neo-Kaleckian model we have

$$
g_{K}^{*}=g_{I}=\left(\frac{s_{\pi}(1-\omega)}{v}\right) u^{*}-\delta .
$$

Now, solving the last equation for the equilibrium degree of capacity utilization we obtain:

$$
u^{*}=\frac{v\left(g_{I}+\delta\right)}{s_{\pi}(1-\omega)} .
$$

Equation (21) shows the determinants of the required degree of capacity utilization $u^{*}$ in the simplified version of the neo-Kaleckian model here presented. This latter rate is the one that reconciles the rate of capital accumulation with the pace of economic growth and, therefore, allows the existence of an equilibrium growth path in the model. Observe that, in its role as an adjusting variable, the equilibrium degree of capacity utilization has to be able to assume any value between zero and one in the long run, no matter how implausible this may be. Therefore the neo-Kaleckian model is not compatible with the related notions of planned spare capacity and normal (or desired) capacity utilization rate. Indeed, if we suppose the existence of a normal degree of capacity utilization, the closure provided by the model implies that it would be possible to have large and persistent deviations of the equilibrium degree of capacity utilization from its normal level and also that such divergence would not have any further repercussions on capitalist investment decisions. ${ }^{19}$ It is important to note that the required long-run endogeneity of the equilibrium degree of capacity utilization does not depend on the particular specification for the investment function adopted here, being in fact valid for all the usual specifications of the investment function in neo-Kaleckian models. ${ }^{20}$ Actually, the necessity concerning the variability of the equilibrium degree of capacity utilization follows from the specification of the consumption function and not from any particular formulation of the investment function adopted in the model. As we argued above, it is the rigidity of the investment share of output implied by the exogeneity of the saving ratio that leads to the requirement of the long-run variability of the equilibrium capacity utilization rate.

Furthermore, note that admitting that the capital stock adjustment principle regulates investment decisions in the context of a neo-Kaleckian model only leads to an instability process of the Harrodian type. ${ }^{21}$ Indeed, suppose, following Skott (2012), that in trying to

19. Compare equation (21) with the theoretical closure associated with the Sraffian supermultiplier growth model as represented by equation (14) above.

20. For instance, the result under discussion is valid for the investment function given by equation (22), in which the equilibrium rate of capacity utilization is given by $u^{*}=v(\alpha+\delta+\rho(1-\omega)) /\left(s_{\pi}(1-\omega)-\beta v\right)$. The same point is valid for other investment functions that frequently appear in the neo-Kaleckian growth literature and, in particular, it is valid in the case of the investment function given by $g_{I t}=\alpha+\beta\left(u_{t}-\mu\right)$ with $\alpha, \beta>0$ and $\mu$ exogenous. Note that in the latter investment function the normal degree of capacity utilization $\mu$ appears as an argument of the investment function. Nonetheless, the endogenous character of the equilibrium degree of capacity utilization is also maintained in this case and the corresponding value of the equilibrium rate is given by $u^{*}=(v(\alpha+\delta-\beta \mu)) /\left(s_{\pi}(1-\omega)-\beta v\right)$.

21. On this point, see Commiteri (1986) and Cesaratto (2015). See also Hein et al. (2012) and Lavoie (2014) for surveys on Harrodian instability in neo-Kaleckian growth models once an adjustment towards normal capacity utilization rate is admitted. 
adjust the actual degree of capacity utilization to its normal level, capitalist firms change the investment growth rate according to $\dot{g}_{I}=\eta\left(u_{t}-\mu\right), \eta>0$. Thus, in the equilibrium path of this particular model (that is, with $\dot{g}_{I}=\dot{u}=0$ ), we would have $u^{*}=\mu$ and $g_{I}^{*}=\left(s_{\pi}(1-\omega) / v\right) \mu-\delta$. Now, if initially we have $u_{0}=\mu$ and $g_{I 0} \gtrless g_{I}^{*}$, then, according to equation (20), we would have $\dot{u} \gtrless 0$, which implies that thereafter we would have $u_{t} \gtrless \mu$ and, hence, $\dot{g}_{I} \gtrless 0$ and $g_{I t} \gtrless g_{I}^{*}$. So the equilibrium rate of growth would be unstable. Thus, according to the neo-Kaleckian growth model, we would have a dilemma: either, we assume away the possibility of an adjustment of the actual degree of capacity utilization towards its normal level and admit the possibility of obtaining an equilibrium path with an implausibly high or low equilibrium degree of capacity utilization or we allow an adjustment of the actual to the normal degree of capacity utilization and obtain an unstable growth trajectory as we just saw. Observe, however, that the dilemma exists only if we restrict ourselves to the set of assumptions of the neo-Kaleckian model. In fact, once we admit the existence of an autonomous component in aggregate consumption the saving ratio becomes an endogenous variable and the investment share of output can change allowing the adjustment of the actual degree of capacity utilization to its normal level, as we have in the Sraffian supermultiplier growth model (Serrano 1995a). ${ }^{22}$

Finally, we shall analyse the role of income distribution in the neo-Kaleckian growth model. Thus, in the very simple version of the model presented here there is no relationship between the pace of economic growth and the level of functional income distribution. Since the investment growth rate is supposed to be an exogenous variable in the model, the equilibrium rate of output growth does not affect and is not affected by the level of the wage share of output. Nevertheless, a change in the wage share has a level effect over the equilibrium value of output according to the simple neo-Kaleckian model under analysis. In fact, an increase (decrease) in the wage share, raises (reduces) the value of the multiplier $1 /\left(s_{\pi}(1-\omega)\right)$ and, through it, such a change has a positive (negative) level effect on equilibrium output. These two latter results are shared with the Sraffian supermultiplier growth model. On the other hand, in contrast with the latter model, from equation (21) we can see that, in the neo-Kaleckian model, an increase (decrease) in the wage share leads to an increase (a reduction) in the equilibrium degree of capacity utilization. A model that presents this type of result is classified in the neo-Kaleckian literature as a 'stagnationist' or 'wage-led aggregate demand' model. ${ }^{23}$

We must say, however, that the independence between the pace of economic growth and income distribution in the simple version of the neo-Kaleckian model presented above is a direct consequence of the specific investment function adopted, which, as we saw, assumes the rate of investment growth to be completely exogenous. Indeed, if we consider the more general formulations of the investment function in the neo-Kaleckian models, then we can obtain alternative causal relationships running from income distribution to the rate of growth of the economy.

So let us consider, for instance, a linear version of the investment function suggested by Bhaduri/Marglin (1990) and Marglin/Bhaduri (1990):

$$
g_{I t}=\alpha+\beta u_{t}+\rho(1-\omega),
$$

22. See Lavoie (2014; 2016), Allain (2015), and Dutt (2016) for growth models that come from the Kaleckian tradition pointing in the direction of the closure provided by the supermultiplier growth model.

23. See Blecker (2002) for discussion of the neo-Kaleckian models based on this type of classification. 
where $\alpha>0$ is an autonomous component of the investment function, $\beta>0$ is a parameter measuring the sensitivity of the growth rate of investment to the rate of capacity utilization, and $\rho>0$ is a parameter measuring the sensitivity of the investment growth rate with respect to the profit share (that is, $(1-\omega)$ ).

As can be seen from the equation above, the introduction of an induced component $\beta u_{t}$ in the investment function turns the investment growth rate into an endogenous variable of the model that positively depends on the actual degree of capacity utilization. Blecker (2002) shows that the specification of the investment function above implies the existence of a positive relationship between the wage share and the equilibrium value of the degree of capacity utilization. ${ }^{24}$ Moreover, we can verify that the higher the value of $\rho$, the lower the positive (and indirect) effect of a change of the wage share exerted through the equilibrium degree of capacity utilization and the higher the direct contribution of a change in the wage share through the third term on the right-hand side of equation (22). Hence, for a sufficiently low value of $\rho$ the positive effect of a modification in the wage share on the investment growth rate through the capacity utilization rate dominates the direct negative effect related to the term $\rho(1-\omega)$. In this case, according to the neo-Kaleckian literature, the model would produce a wage-led growth pattern. On the other hand, for a sufficiently high value of $\rho$ we would have the opposite situation and the model would generate a profit-led pattern of economic growth. In both cases, a change in income distribution has a permanent growth effect. The existence of a relationship between economic growth and income distribution featured in the last version of the neo-Kaleckian model also characterizes the Cambridge growth model, as we saw. In the latter model there is an inverse relationship between the wage share and the rate of output growth, whereas the last specification of the neoKaleckian model admits either a positive (in the wage-led growth case) or a negative (in the profit-led growth case) relationship between the two variables. In any case, in contrast to these possible wage-led or profit-led growth regimes, the absence of any direct permanent (or mechanical) relationship between income distribution and the trend rate of economic growth (apart from a wage-led level effect) are important features of the Sraffian supermultiplier growth model. ${ }^{25}$

Note, however, that the more general neo-Kaleckian investment function (equation (22) above) is not without its own problems. The component that captures the influence of the degree of capacity utilization, which has been commonly referred to as an 'accelerator effect' (Marglin/Bhaduri 1990), is not really an accelerator type of analysis. As we discussed above, the necessary condition for the adjustment of capacity to demand is that investment should be able to grow faster than aggregate demand when there is overutilization and slower than aggregate demand when there is underutilization. Because consumption is completely induced and the aggregate marginal propensity to consume (and save) is exogenously given in the neo-Kaleckian model, investment can never grow at a different

24. He also shows that if a non-linear specification of the positive effect of the share of profit on the investment function was adopted it would be possible to obtain a negative relationship between the degree of capacity utilization and the wage share. In this case, the level of output would be profitled. However, Lavoie (2014) shows that we can obtain this result even retaining the linear specification of the investment function if we admit negative values for the parameter $\alpha$.

25. And, interestingly enough, the Sraffian supermultiplier is more similar in this respect to Kalecki's (1971) own views on the 'trend' (which in terms of equation (22) above would imply that both $\beta$ and $\rho$ are equal to zero) than the neo-Kaleckian models. 
rate than aggregate consumption and aggregate demand. ${ }^{26}$ Moreover, once we admit the existence of a normal degree of capacity utilization, then the inclusion of the second term of the investment function (22) does not help to bring the economy closer to this normal degree of utilization. For instance starting from an equilibrium with a normal degree of utilization, if the exogenous term in the investment function $(\alpha)$ increases (falls), the new equilibrium degree of capacity utilization will be further above (below) the normal degree if the reaction parameter $\beta$ is positive than in the case in which $\beta$ is zero, that is, the situation in which investment is not sensitive to degree of capacity utilization. ${ }^{27}$ This result further confirms that this term of the investment function does not capture a capital stock adjustment or an accelerator effect.

Turning to the third term on the right-hand side of equation (22), the problem is that there seems to be no good theoretical reason to make investment a direct function of the level of the profit share, independently from the effect of the latter on aggregate demand. In the most favorable interpretation, investors would be reacting to the higher normal rate of profit that could be obtained in new investments operating at the normal degree of utilization (see Lavoie 1995). But why exactly would firms invest more than justified by actual/expected demand if the profit share increases? The inclusion of this component on the investment function, in addition to the effect of demand variables, requires us to assume that firms invest to create productive capacity which they either do not think they need or which they will quickly find out they did not need. ${ }^{28,29}$ In fact, in the particular case in which output happens to be wage-led, a higher profit share will reduce demand and the actual degree of capacity utilization. Thus, only if investment is sufficiently reduced (instead of increased) when the share of profits rises, the actual degree of capacity utilization will tend to its normal level, and this higher normal rate of profits may in fact be realized. On the other hand, if output happens to be profitled, investment will already increase as a direct consequence of the higher actual degree of capacity utilization and it is not clear why firms would invest to create more capacity than is needed to obtain normal utilization.

\section{FINAL REMARKS}

Table 1 summarizes the principal results obtained from the comparative analysis above. We have shown how the Sraffian supermultiplier model, with its hypotheses of growing non-capacity-creating autonomous demand and an investment function based on the

26. Note that in the usual stationary state multiplier-accelerator models of the business cycle there is always some autonomous component in demand that does not create capacity, and thus demand during the cycle grows at different rates from investment. In this respect see Matthews (1959) for a very clear exposition of these models.

27. Taking the partial derivative of equilibrium degree of capacity utilization $u^{*}=v(\alpha+\delta+$ $\rho(1-\omega)) /\left(s_{\pi}(1-\omega)-\beta v\right)$ with respect to $\alpha$, we obtain $\partial u^{*} / \partial \alpha=v /\left(s_{\pi}(1-\omega)-\beta v\right)$. Thus a positive $\beta$ implies a higher value of $\partial u^{*} / \partial \alpha$ than in the case in which $\beta=0$.

28. The argument would hold symmetrically in the case in which the profit share decreases. Investment may fall down to zero if the profit share falls below a minimum acceptable level. But above such a lower limit there is no good reason to believe that a higher or a lower profit share should have any direct effect on investment.

29. For the Sraffian criticism of a positive direct effect of the profit share (or normal rate of profits) on investment see Garegnani (1962 [2015]), Petri (1993) and Cesaratto (2015). For a detailed critique of the Marglin-Bhaduri version of the neo-Kaleckian growth model based on the Sraffian supermultiplier model, see Pariboni (2015). 


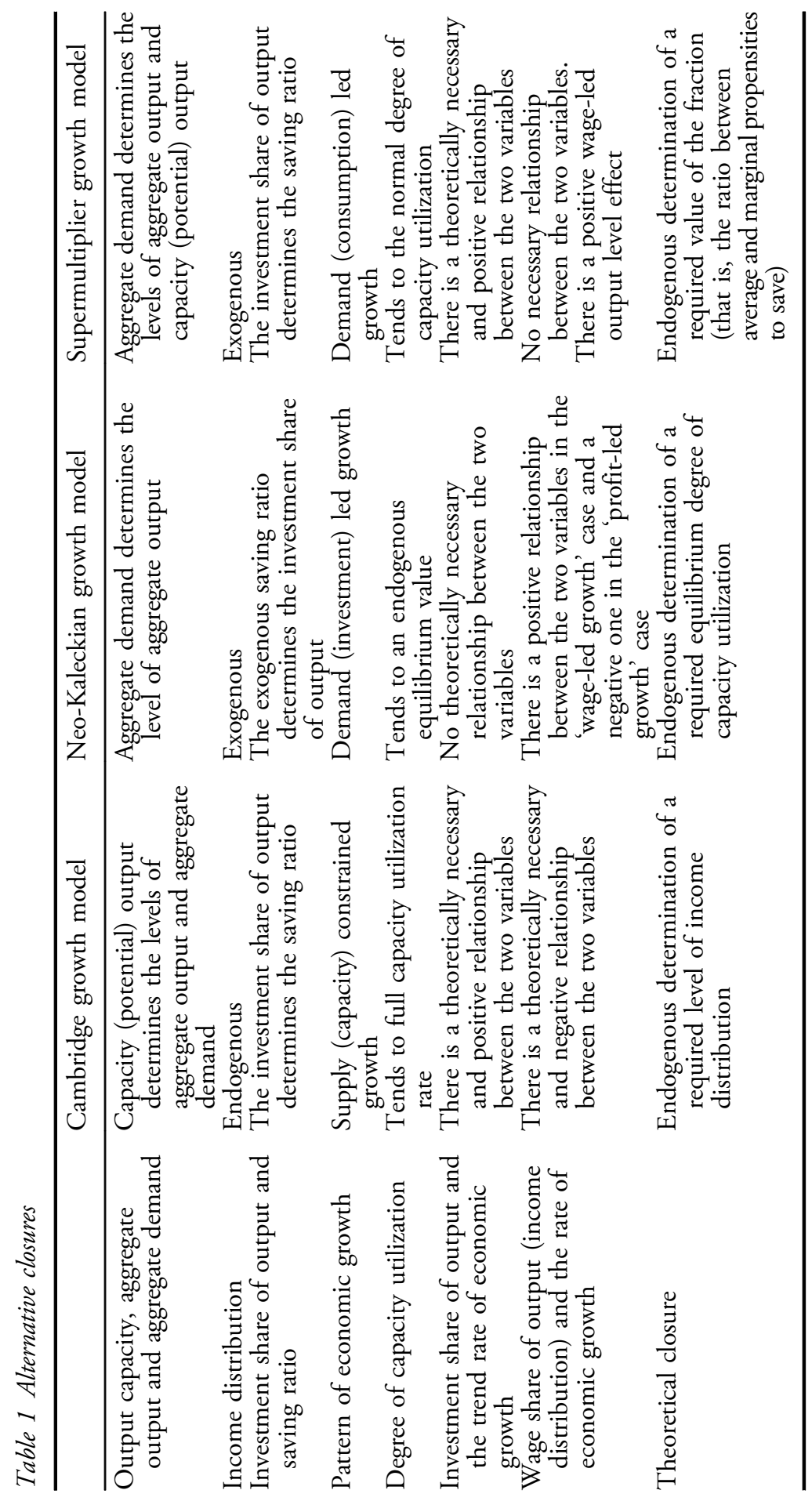


capital stock adjustment principle, provides us with a distinct and more satisfactory closure for heterodox growth theory. Using this closure, changes in the propensity to invest can determine the saving ratio by means of changes in the fraction, that is, the ratio of the average to the marginal propensity to save. We have also shown how gradual changes in the marginal propensity to invest make it possible for capacity to adjust to demand and are able to reconcile demand-led growth, exogenous distribution, and a tendency to move towards the normal degree of capacity utilization, even across steady states. The supermultiplier model also does not impose the existence of any necessary a priori theoretical relationship between income distribution and economic growth and, therefore, leaves room for the separate determination of income distribution from outside the model by political, historical, and economic factors. Finally, the closure of the Sraffian supermultiplier shows that giving up the sensible idea that output is demand-determined in the long run at the cost of obtaining a tendency towards normal utilization, as in the Cambridge model, or else allowing the possible prevalence of arbitrarily high or low permanent deviations of the actual degree of capacity utilization from its normal level are not the only available alternatives to heterodox growth theory.

\section{REFERENCES}

Allain, O. (2015): Tackling the instability of growth: a Harrodian model with an autonomous expenditure component, in: Cambridge Journal of Economics, 39(5), 1351-1371.

Bhaduri, A., Marglin, S. (1990): Unemployment and the real wage: the economic basis for contesting political ideologies, in: Cambridge Journal of Economics, 14(4), 375-393.

Blecker, R. (2002): Distribution, demand and growth in neo-Kaleckian macro models, in: Setterfield, M. (ed.), Demand-led Growth: Challenging the Supply-side Vision of the Long Run, Aldershot, UK and Brookfield, VT: Edward Elgar, 129-152.

Cesaratto, S. (2015): Neo-Kaleckian and Sraffian controversies on the theory of accumulation, in: Review of Political Economy, 27(3), 154-182.

Chenery, H.B. (1952): Overcapacity and the acceleration principle, in: Econometrica, 20(1), 1-28.

Ciccone, R. (1986): Accumulation and capacity utilization: some critical considerations on Joan Robinson's theory of distribution, in: Political Economy: Studies in the Surplus Approach, 2(1), 17-36.

Ciccone, R. (1987): Accumulation, capacity utilization and distribution: a reply, in: Political Economy: Studies in the Surplus Approach, 3(1), 97-111.

Ciccone, R. (2011): Capacity utilization, mobility of capital and the classical process of gravitation, in: Ciccone, R., Gehrke, C., Mongiovi, G. (eds), Sraffa and Modern Economics, Vol. 2, London: Routledge, 76-86.

Commiteri, M. (1986): Some comments on recent contributions on capital accumulation, income distribution and capacity utilization, in: Political Economy: Studies in the Surplus Approach, 2(2), 161-186.

Davidson, P. (1972): Money and the Real World, London: Macmillan.

Dutt, A.K. (1984): Stagnation, income distribution and monopoly power, in: Cambridge Journal of Economics, 8(1), 25-40.

Dutt, A.K. (1990): Growth, Distribution and Uneven Development, Cambridge, UK: Cambridge University Press.

Dutt, A.K. (2011): The role of aggregate demand in classical-Marxian models of economic growth, in: Cambridge Journal of Economics, 35(2), 357-382.

Dutt, A.K. (2016): Growth and distribution with exogenous autonomous demand growth and normal capacity utilization, Mimeo, University of Notre Dame.

Freitas, F. (2002): Uma Análise da Evolução das Ideias de Kaldor sobre o Processo de Crescimento Econômico [An analysis of the evolution of Kaldor's ideas on the process of economic growth], Unpublished PhD thesis (in Portuguese), Federal University of Rio de Janeiro, Rio de Janeiro.

Freitas, F. (2009): O Papel da Teoria da Distribuição nos Modelos Crescimento com Pleno Emprego de Kaldor: uma avaliação crítica [The role of the theory of distribution in Kaldor's 
full employment growth models: a critical assessment], Mimeo (in Portuguese), Federal University of Rio de Janeiro, Rio de Janeiro.

Freitas, F., Serrano, F. (2015): Growth rate and level effects, the stability of the adjustment of capacity to demand, and the Sraffian supermultiplier, in: Review of Political Economy, 27(3), 258-281.

Garegnani, P. (1962 [2015]): The problem of effective demand in Italian economic development: on the factors that determine the volume of investment, in: Review of Political Economy, 27(2), 111-133.

Garegnani, P. (1992): Some notes for an analysis of accumulation, in: Halevi, J., Laibman, D., Nell, E.J. (eds), Beyond the Steady State: A Revival of Growth Theory, London: Macmillan, 47-72.

Goodwin, R. (1951): The nonlinear accelerator and the persistence of business cycles, Econometrica, 19(1), 1-17.

Hein, E., Lavoie, M., van Treeck, T. (2012): Harrodian instabilty and the 'normal rate' of capacity utilization in neo-Kaleckian models of distribution and growth: a survey, in: Metroeconomica, 63(1), 139-169.

Kaldor, N. (1955/1956): Alternative theories of distribution, in: Review of Economic Studies, 23(2), 83-100.

Kaldor, N. (1957 [1960]): A model of economic growth, in: Kaldor, N., Essays on Economic Stability and Growth, Glencoe, IL: Free Press, 259-300.

Kaldor, N. (1958 [1978]): Capital accumulation and economic growth, in: Kaldor, N., Further Essays on Economic Theory, New York: Holmes \& Meier, 1-53.

Kaldor, N. (1962 [1978]): A new model of economic growth, in: Kaldor, N., Further Essays on Economic Theory, New York: Holmes \& Meier, 54-80.

Kalecki, M. (1971): Selected Essays on the Dynamics of Capitalist Economy 1933-1970, Cambridge, UK: Cambridge University Press.

Lavoie, M. (1995): The Kaleckian model of growth and distribution and its neo-Ricardian and neoMarxian critiques, in: Cambridge Journal of Economics, 19(6), 789-818.

Lavoie, M. (2014): Post-Keynesian Economics: New Foundations, Aldershot, UK and Brookfield, VT: Edward Elgar.

Lavoie, M. (2016): Convergence towards the normal rate of capacity utilization in neo-Kaleckian models: the role of non-capacity creating autonomous expenditures, in: Metroeconomica, 67(1), $172-201$.

Lee, F. (1999): Post Keynesian Price Theory, Cambridge, UK: Cambridge University Press.

Marglin, S.A., Bhaduri, A. (1990): Profit squeeze and Keynesian theory, in: Marglin, S.A., Schor, J.B. (eds), The Golden Age of Capitalism, Oxford: Oxford University Press, 153-186.

Matthews, R.C.O. (1959): The Trade Cycle, Cambridge, UK: James Nisbet.

Pariboni, R. (2015): Autonomous demand and the Marglin-Bhaduri model: a critical note, Universitá di Siena, Quaderni del Dipartimento di Economia Politica Statistica, no 715.

Petri, F. (1993): Critical notes on Kalecki's theory of investment, in: Mongiovi, G., Ruhl, C. (eds), Macroeconomic Theory: Diversity and Convergence, Aldershot, UK and Brookfield, VT: Edward Elgar, 189-207.

Robinson, J. (1962): Essays on the Theory of Economic Growth, London: Macmillan.

Rowthorn, B. (1981): Demand, real wages and economic growth, in: Thames Papers in Political Economy, Autumn, 1-39.

Serrano, F. (1995a): Long period effective demand and the Sraffian supermultiplier, in: Contributions to Political Economy, 14, 67-90.

Serrano, F. (1995b): The Sraffian supermultiplier, Unpublished PhD thesis, University of Cambridge, UK.

Skott, P. (2012): Theoretical and empirical shortcomings of the neo-Kaleckian investment function, in: Metroeconomica, 63, 109-138.

Steindl, J. (1952): Maturity and Stagnation in American Capitalism, Oxford: Basil Blackwell.

Steindl, J. (1979): Stagnation theory and stagnation policy, in: Cambridge Journal of Economics, 3(1), $1-14$.

Steindl, J. (1989): Distribution and growth, in: Political Economy: Studies in the Surplus Approach, 1(1), 53-68.

Sylos-Labini, P. (1962): Oligopoly and Technical Progress, London: Oxford University Press.

Vianello, F. (1985): The pace of accumulation, in: Political Economy: Studies in the Surplus Approach, $1(1), 69-87$. 